\title{
THE EFFECT OF L-NOREPINEPHRINE ON CARDIAC OUTPUT IN THE ANESTHETIZED DOG DURING GRADED HEMORRHAGE 1
}

\author{
By J. P. GILMORE, C. M. SMYTHE, 2 AND S. W. HANDFORD ${ }^{3}$ \\ (From the Department of Physiology, Naval Medical Field Research Laboratory, \\ Camp Lejeune, N.C.)
}

(Submitted for publication November 16, 1953 ; accepted February 18, 1954)

Clinical reports have recently suggested that 1-norepinephrine is a valuable agent in the treatment of shock (1-3). It has been found relatively more effective in those cases in which there is no major decrease in blood volume, such as in shock due to drug sensitivity, myocardial infarction, overwhelming infection and post-operative hypotension unresponsive to transfusion. Also, some cases of surgical or oligemic shock are reported in which it has been used with success (4-6). The rationale for the use of 1 -norepinephrine in shock rests on the observation that its administration is followed by restoration of blood pressure and general clinical improvement. However, since there is a body of surgical opinion which holds that pressor drugs are contraindicated in the treatment of hemorrhagic hypotension, the present series of experiments was designed to define the circulatory responses of the dog to 1-norepinephrine during graded hemorrhage. Cardiac output, arterial pressure and total peripheral resistance were the parameters measured.

The effects of 1-norepinephrine on the normal human circulation are well known (7). The drug elicts a bradycardia, an increase in systolic and diastolic arterial pressures, an increase in total peripheral resistance, a slight decrease or no change in cardiac output, an increase in coronary blood flow, a marked decrease in renal, cutaneous, skeletal muscular and cerebral blood flows and no change of estimated splanchnic blood flow (7). From these circulatory responses, it is apparent that coronary and hepatic blood flow are maintained or increased under the influence of 1 norepinephrine, while flow in other vascular cir-

1 This work is not to be construed as necessarily reflecting the views of the Department of the Navy.

2 LT MC USNR. Present address: 31 Legare Street, Charleston, S. C.

${ }^{3}$ CDR MSC USN. cuits is decreased. Current experimental evidence places the blame for the development of irreversible surgical shock on failure of the liver and heart. If 1 -norepinephrine given to the shocked animal also produces relative increases of flow through these two vulnerable, vital organs, therein may lie a rationale for its use other than its vasoconstrictor action.

\section{METHODS}

Eighteen fasting, mongrel dogs (mean weight $10.6 \mathrm{Kg}$.) were anesthetized with morphine tartrate, $3 \mathrm{mg}$. per $\mathrm{Kg}$. intramuscularly, followed in 30 minutes by chloralose, 48 mg. per $\mathrm{Kg}$., and urethane, $480 \mathrm{mg}$. per $\mathrm{Kg}$. intravenously. The right brachial artery, both femoral arteries, a femoral vein and a jugular vein were exposed and cannulated. Arterial pressure was measured with a capacitance type electromanometer and recorded on a multi-channel oscillograph. Mean arterial pressure was obtained by electrical integration of the electromanometric output. Oxygen was administered by intra-tracheal catheter. Heparin was used as an anticoagulant. Cardiac output was determined by the T-1824 Blue dye injection method. based on the Stewart principle (8). The dye concentration curve was measured with a calibrated dye photometer (9), the output of which was recorded on the oscillograph. Surface area was calculated from the nomogram of Cowgill and Drabkin (10). The base line for arterial pressure was taken at the skin of the back of the dog.

Experimental hemorrhagic shock was produced by the two-stage bleeding technique described by Wiggers (11). After the animals had been anesthetized and all apparatus was in satisfactory working order, two determinations of cardiac output, pulse rate, central venous and arterial pressures were made in close sequence. L-norepinephrine ${ }^{4}$ was then administered intravenously by a constant infusion pump for ten minutes after which time the same determinations were repeated. (This series of determinations constitute the control period.) The 1-norepinephrine infusion was then discontinued. After arterial pressure had returned to the base line level, bleeding was begun by syringe at a rate of $50 \mathrm{ml}$. per min. and continued until a pressure of $50 \mathrm{~mm}$. $\mathrm{Hg}$ was reached. This level was maintained for several minutes. Another set of deter-

\footnotetext{
Levophed, 0.1 per cent, Winthrop-Stearns, New York 18, N. Y.
} 
TABLE I

Effect of l-norepinephrine on mean arterial pressure*

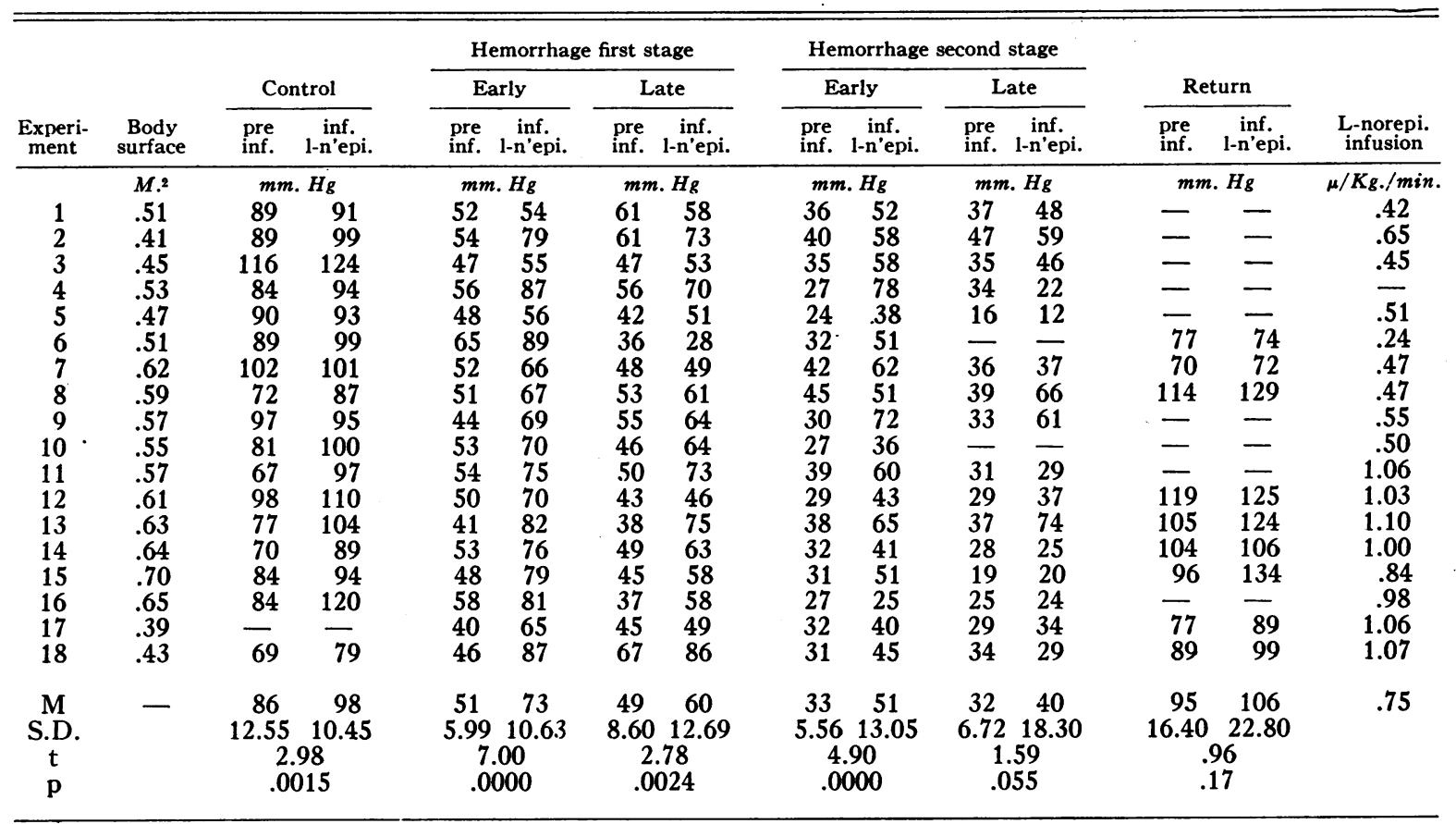

* All figures are the means of two determinations.

TABLE II

Effect of l-norepinephrine on cardiac output *



* All figures are the means of two determinations.

$\dagger$ Not included in statistical analysis. 
minations was then made before and during the 1-norepinephrine infusion which was given at the same rate and for the same time as during the control period (early first stage of hemorrhage). Arterial pressure was held at 50 $\mathrm{mm}$. $\mathrm{Hg}$ for 75 minutes and measurements were made before and during the 1-norepinephrine infusion as above (late first stage of hemorrhage). The animals were next bled at $50 \mathrm{ml}$. per min. to a pressure of $30 \mathrm{~mm}$. $\mathrm{Hg}$. Measurements were again made before and during 1-norepinephrine as described above (early second stage of hemorrhage). Pressure was maintained at $30 \mathrm{~mm} . \mathrm{Hg}$ for 75 minutes and the sequence of determinations was then repeated (late second stage of hemorrhage). All blood was next reinfused intravenously, blood pressure allowed time to stabilize, and the determinations made once again before and during the 1-norepinephrine infusion (return period). In all experiments, the 1-norepinephrine infusion was maintained at the same rate from beginning to end of the experiment regardless of the condition of the animal. No blood was administered to the animals during the determinations. The blood withdrawn for cardiac output determinations was replaced immediately after each pair of determinations had been completed. ${ }^{5}$

5 Cardiac output determinations were made in pairs and the data presented in the tables are the means of each pair. Statistical analysis of the difference between all

\section{RESULTS}

Data from eighteen experiments are presented in Tables I, II, and III. Figure 1 is a typical recording of the T-1824 dye concentration curves, right auricular, and femoral arterial pressures obtained from an animal in the early first stage of hemorrhage before and during the infusion of l-norepinephrine. In ten experiments, an average l-norepinephrine infusion of $0.47 \mu$ per $\mathrm{Kg}$. per min. was given and in eight $1.02 \mu$ per $\mathrm{Kg}$. per min. No significant difference is apparent when these two groups are treated separately.

In the control period 1-norepinephrine produced the expected increase in mean arterial pressure $(t=2.98, p=.0015)$. However, the response of cardiac output to the drug during this period varied. At times it increased, sometimes it de-

paired samples at all stages of hemorrhage gives the following results : mean of the first determination $645 \mathrm{ml}$. per min.; S.D. \pm 512 . Mean of the second determination 630 ml. per min.; S.D. \pm 548 . The difference between the means is not significant $(t=.276, p=.40)$.

TABLE III

Effect of l-norepinephrine on total peripheral resistance*

\begin{tabular}{|c|c|c|c|c|c|c|c|c|c|c|c|c|}
\hline \multirow[b]{3}{*}{$\begin{array}{c}\text { Experi- } \\
\text { ment }\end{array}$} & & & \multicolumn{4}{|c|}{ Hemorrhage first stage } & \multicolumn{4}{|c|}{ Hemorrhage second stage } & & \\
\hline & \multicolumn{2}{|c|}{ Control } & \multicolumn{2}{|c|}{ Early } & \multicolumn{2}{|c|}{ Late } & \multicolumn{2}{|c|}{ Early } & \multicolumn{2}{|c|}{ Late } & \multicolumn{2}{|c|}{ Return } \\
\hline & $\begin{array}{l}\text { pre } \\
\text { inf. }\end{array}$ & $\underset{\text { inf.epi. }}{\text { inf. }}$ & $\begin{array}{l}\text { pre } \\
\text { inf. }\end{array}$ & $\underset{\text { l-n'epi. }}{\text { inf. }}$ & $\begin{array}{l}\text { pre } \\
\text { inf. }\end{array}$ & $\underset{\text { 1-n'epi. }}{\inf .}$ & $\begin{array}{l}\text { pre } \\
\text { inf. }\end{array}$ & $\underset{1-n^{\prime} \text { epi. }}{\inf }$ & $\begin{array}{l}\text { pre } \\
\text { inf. }\end{array}$ & $\underset{\text { inf'epi. }}{\operatorname{ninf}}$ & $\begin{array}{l}\text { pre } \\
\text { inf. }\end{array}$ & $\underset{\text { inf. nopi. }}{\text { ing. }}$ \\
\hline & \multicolumn{2}{|c|}{ PRU† } & \multicolumn{2}{|c|}{$P R U$} & \multicolumn{2}{|c|}{$P R U$} & \multicolumn{2}{|c|}{$P R U$} & \multicolumn{2}{|c|}{$P R U$} & \multicolumn{2}{|c|}{$P R U$} \\
\hline 1 & .0393 & .0545 & .0585 & .0513 & .0550 & .0403 & .0968 & .1083 & .0979 & .1193 & - & - \\
\hline 2 & .0458 & .0578 & .0555 & .0527 & .0741 & .0703 & .0635 & .0855 & .0760 & .0840 & - & - \\
\hline 3 & .0778 & .0474 & .0588 & .0407 & .0653 & .0510 & .0778 & .0598 & .0635 & .0537 & - & - \\
\hline 4 & .0438 & .0472 & .0652 & .0700 & .0707 & .0537 & .0483 & .0755 & .0502 & .0502 & - & - \\
\hline 5 & .0438 & .0397 & .1290 & .1333 & .1228 & .0877 & .0890 & .0868 & .0667 & .0425 & - & - \\
\hline 6 & .0367 & .0350 & .1375 & .1207 & .1817 & .1260 & .1617 & .1308 & - & - & .1010 & .1208 \\
\hline 7 & .0640 & .0470 & .0535 & .0518 & .0580 & .0495 & .0648 & .0647 & .0667 & .0772 & .0321 & .0315 \\
\hline 8 & .0522 & .0580 & .0595 & .0627 & .0510 & .0558 & .0635 & .0560 & .0738 & .0902 & .0699 & .0763 \\
\hline 9 & .0545 & .0565 & .0797 & .0837 & .0745 & .0746 & .0668 & .0960 & .0965 & .0997 & - & - \\
\hline 10 & .0409 & .0391 & .0600 & .0607 & .0560 & .0503 & .0340 & .0381 & - & - & - & - \\
\hline 11 & .0332 & .0521 & .0443 & .0435 & .0267 & .0433 & .0683 & .0855 & .0770 & .0743 & - & - \\
\hline 12 & .0236 & .0242 & .0469 & .0407 & .0373 & .0310 & .0537 & .0543 & .0672 & .0560 & .0607 & .0947 \\
\hline 13 & .0340 & .0634 & .0455 & .0621 & .0423 & .0555 & .0653 & .0867 & .0648 & .1003 & .0691 & .0951 \\
\hline 14 & $.0208 \ddagger$ & $.0135 \ddagger$ & .0505 & .0523 & .0329 & .0273 & .0344 & .0358 & .0692 & .0425 & .0530 & .0635 \\
\hline 15 & .0513 & $.0527^{\circ}$ & .0437 & .0465 & .0478 & .0412 & .0318 & .0324 & .0283 & .0283 & .0241 & .0455 \\
\hline 16 & .0455 & .0793 & .0736 & .0637 & .0467 & .0478 & .0548 & .0453 & .0595 & .0755 & - & - \\
\hline 17 & - & - & .0813 & .0933 & .1087 & .0983 & .0988 & .0990 & .1510 & .1618 & .0831 & .0915 \\
\hline 18 & .0570 & .0835 & .2217 & .1700 & .1720 & .2200 & .2348 & .2678 & .2983 & .2102 & .1701 & .2141 \\
\hline M & .0467 & .0523 & .0752 & .0722 & .0725 & .0680 & .0782 & .0838 & .0879 & .0854 & .0737 & .0925 \\
\hline S.D. & .0193 & .0150 & .0434 & .0350 & .0443 & .0448 & .0492 & .0532 & .0622 & .0471 & .0434 & .0532 \\
\hline$t$ & & & & 22 & & 36 & .3 & 32 & & 20 & & 77 \\
\hline $\mathrm{p}$ & & & & 42 & & 36 & .3 & 38 & & $\$ 2$ & & 24 \\
\hline
\end{tabular}

* All figures are the means of two determinations.

$\dagger \mathrm{PRU}=\frac{1 \mathrm{~mm} . \mathrm{Hg}}{1 \mathrm{ml} . / \mathrm{min} .}$.

$\ddagger$ Not included in statistical analysis. 




Fig. 1. The Effect of Intravenous L-Norepinephrine on Cardiac Output, Right Auricular Pressure, and Arterial Pressure in the Early First Stage of Hemorrhage (Expt. No. 9) Prior to the Development of IRREVERSIBILITY

Note the decrease in area under the T-1824 dye curve, which is indicative of an increase in cardiac output, during the infusion of 1-norepinephrine. The apparent increase of right auricular pressure is due to shifting of the base line which is set at $9 \mathrm{~mm}$. $\mathrm{Hg}$. The rise of arterial pressure is pronounced $(32 \mathrm{~mm}$. $\mathrm{Hg})$.

creased and sometimes it showed no change. This inconsistent response of cardiac output to l-norepinephrine was reflected in the total peripheral resistance which also showed a wide variation. In short, no consistent hemodynamic pattern could be discerned during the control period other than the increase of mean arterial pressure.

Significant increases of cardiac output occurred during l-norepinephrine infusion, during the early first stage of hemorrhage $(t=3.14, p=.001)$, during the late first stage of hemorrhage $(t=1.75$, $p=.040$ ) and during the early second stage of hemorrhage $(t=2.26, p=.012)$. During the latter three stages, 1-norepinephrine caused an increase in cardiac output during 49 of 51 determinations. There was no significant change of cardiac output during the late second stage of hemorrhage $(t=.75, p=.22)$ or during the return period $(\mathrm{t}=.51, \mathrm{p}=.30)$.

L-norepinephrine also elicited significant increases in mean arterial pressure during the first stage of hemorrhage and the early second stage of hemorrhage. This rise of pressure was due to increases in both systolic and diastolic pressures. As in the case of cardiac output, there was no sig- nificant change in pressure due to the drug in the late second stage of hemorrhage or in the return period. In those instances in which the infusion of l-norepinephrine was accompanied by a decrease of arterial pressure, the animals were in the "takeup" period of hemorrhagic shock and arterial pressure was already failing prior to the infusion.

Although the mean total peripheral vascular resistance during the 1-norepinephrine infusion rose in all periods observed (Table III), in no instance is the rise statistically significant.

During experiments 1 to 9, right atrial pressure was measured. In the control period 1-norepinephrine caused a rise of mean right atrial pressure $(2.8 \mathrm{~mm}$. $\mathrm{Hg}$ to $4.1 \mathrm{~mm}$. $\mathrm{Hg}$ ), which is not significant $(\mathrm{p}=.12)$. There was no change of mean auricular pressure during the remaining stages of the experiment.

\section{DISCUSSION}

The increase in mean arterial pressure observed in response to 1-norepinephrine during the control period has been widely reported (7). Other observers have also noted the variation of response of cardiac output to the drug $(7,12)$. In the 
presently reported series of experiments the effect on cardiac output during the control period was not uniform, varying from a 28 per cent decrease to a 75 per cent increase. However, in most experiments there was little change of resting cardiac output.

Brewster, Isaacs, and Wain $\phi$-Andersen (12) and Zanetti and Opdyke (13) have demonstrated that the response of both central and peripheral circulations to pressure amines is influenced to a great extent by the vasomotor status of the peripheral vascular bed prior to administration of the drug. Thus, comparison of data obtained from anesthetized dogs with that from alert human beings is not entirely justified. Others (14) have also stressed that the response of the circulation to different anesthetics may vary greatly. Brewster, Isaacs, and Wain $\phi$-Andersen (12) found that 1-norepinephrine may effect a marked increase of cardiac output in the anesthetized dog. These facts probably account for the variations in response of cardiac output and peripheral resistance seen during the control periods of the present experiments.

The increase in cardiac output produced by the infusion of 1-norepinephrine during the early stages of hemorrhagic shock was due to an increased stroke volume, since no tachycardia was observed: Two possible explanations for such an increased stroke volume may be offered : first, a direct central circulatory effect due to the direction stimulation of the myocardium by 1-norepinephrine; second, an increase of venous return due to a peripheral circulatory effect of the drug. No effort has been made to assess the possible role of direct myocardial stimulation.

An increase in venous return may be explained by an increase in the effective circulating blood volume. In the shocked animal, a significant portion of the blood volume may lie stagnant in the veins and venules not immediately available to the general circulation. Thus, any agent causing venoconstriction may make a greater amount of blood available to the effective circulating volume. L-norepinephrine is a venoconstrictor and constricts the vessel of the spanchnic area as well as those of the muscle and skin (7). Hence, in response to the drug, the intravascular volume of the venous bed may be reduced and more blood made available to the effective circulation. These two factors would, in turn, increase venous return and, therefore, cardiac output.

A preparation has recently been devised with which changes of venous return and of available circulating blood volume may be demonstrated (15). Blood is diverted from the inferior and superior venae cavae into a reservoir from which blood is returned to the right heart. In this preparation (in the dog) injections of 1-norepinephrine caused an increase of venous return and eight per cent sustained increment of blood in the reservoir.

During the irreversible stage of shock, in which 1-norepinephrine was not effective in increasing cardiac output, venoconstriction was probably at a minimum due to a complete loss of venous responsiveness. If 1-norepinephrine does play a direct role in stimulating the heart and effecting an increase of cardiac output, it is perhaps due to an increased coronary flow (16) and hence improved myocardial metabolism.

The preparation employed results in 82 per cent mortality after the end of the second stage of hemorrhage, and death within six hours after the reinfusion of the total volume shed (11). Therefore, the failure to demonstrate significant increases in cardiac output and arterial pressure during the late two stages of shock can be attributed to the condition of the animals at this time.

The increase of peripheral resistance occurring after hemorrhage is a well-known phenomenon. Remington and his associates have shown that Dibenamine (Smith, Kline, and French), an adrenergic blocking agent, increases the survival rate of dogs in hemorrhagic shock presumably by preventing vasoconstriction which they believe may be a precipitating factor in irreversibility (17). However, in their experiments the bleeding volume was less than in the unmedicated animals. From these experiments one might conclude that vasoconstrictor agents such as 1-norepinephrine are contraindicated in hemorrhagic hypotension. From the results of the present experiments, it would seem that such a conclusion may be erroneous, since 1-norepinephrine effected no significant increase in peripheral resistance in any of the stages of hemorrhage.

Possible reasons for the lack of rise in peripheral resistance during the control are discussed 
above. In the earlier stages of hemorrhage, the pressure rise effected by 1 -norepinephrine was accompanied by elevations of cardiac output. Late in hemorrhage neither cardiac output nor pressure increased.

The validity of the single dye injection method for determining cardiac output during hemorrhage in the dog is discussed by Hamilton and Remington (18). Others have compared this method with the direct Fick technique over a wide range of conditions and outputs in man (19).

The results of these experiments complement clinical observations of the effect of 1-norepinephrine in oligemic shock. During the early stages of hemorrhagic hypotension when blood volume has not been critically depleted, and during severe hemorrhage prior to the development of irreversibility, the drug effected significant increases in cardiac output and arterial pressure. Moreover, during the experiments, the drug caused no adverse effects. After near fatal exsanguination or peripheral vascular failure, however, 1-norepinephrine was of little therapeutic value. The above results would seem to justify the further clinical investigation of the effects of 1 -norepinephrine in the treatment of oligemic shock pending, or as an adjunct to, whole blood transfusion. The temporary relief afforded by the drug during hemorrhagic hypotension may have significant applications in the treatment of surgical cases provided it is clearly realized that whole blood transfusion is still the primary therapy of oligemic shock.

\section{SUMMARY AND CONCLUSIONS}

In experimental hemorrhagic hypotension in dogs, 1-norepinephrine ( $0.75 \mu$ per min. per $\mathrm{Kg}$.) elicits significant increases of cardiac output and arterial pressure. Later in hemorrhage and after the development of irreversible shock, 1-norepinephrine effects no significant change of arterial pressure or cardiac output. During no stage of hemorrhagic hypotension did the drug elicit an increase of total peripheral resistance.

\section{ACKNOWLEDGMENTS}

We acknowledge with thanks and appreciation the technical assistance of P. J. Stonestreet, HMC, USN, and Mr. R. Jackson.

\section{REFERENCES}

1. Mayer, R. A., and Ruben, J. E., Arterenol (Norepinephrine): I. In the treatment of shock. J. Phila. Gen. Hosp., 1951, 2, 115.

2. Goldenberg, M., Apgar, V., Deterling, R., and Pines, K. L., Nor-epinephrine (Arterenol $\circledast$, Sympathin N) as a pressor drug. J. A. M. A., 1949, 140, 776.

3. Luger, N. M., Kleiman, A., and Fremont, R. E., Treatment of shock with Arterenol. J. A. M. A., 1951, 146, 1592.

4. Kurland, G. S., and Malach, M., The clinical use of nor-epinephrine in the treatment of shock accompanying myocardial infarction and other conditions. New England J. Med., 1952, 247, 383.

5. Cappe, B. E., and Pallin, I. M., Treatment of massive hemorrhage in obstetric cases by transfusion and norepinephrine. Anesthesiology, 1951, 12, 728.

6. Moyer, J. H., Skelton, J. M., and Mills, L. C., Norepinephrine; effect in normal subjects; use in treatment of shock unresponsive to other measures. Am. J. Med., 1953, 15, 330.

7. Barcroft, H., and Swan, H. J. C., Sympathetic Control of Human Blood Vessels. London, Edward Arnold and Co., 1953.

8. Stewart, G. N., The output of the heart in dogs. Am. J. Physiol., 1921, 57, 27.

9. Friedlich, A., Heimbecker, R., and Bing, R. J., A device for continuous recording of concentration of Evans blue dye in whole blood and its application to determination of cardiac output. J. Appl. Physiol., 1950, 3, 12.

10. Cowgill, G. R., and Drabkin, D. L., Determination of a formula for the surface area of the dog together with a consideration of formulae available for other species. Am. J. Physiol., 1927, 81, 36.

11. Wiggers, C. J., Physiology of Shock. New York, The Commonwealth Fund, 1950.

12. Brewster, W. R., Jr., Isaacs, J. P., and Wain $\phi-A n-$ dersen, T., Depressant effect of ether on myocardium of the dog and its modification by reflex release of epinephrine and nor-epinephrine. Am. J. Physiol., 1953, 175, 399.

13. Zanetti, M. E., and Opdyke, D. F., Similarity of acute hemodynamic response to 1-epinephrine and 1-arterenol. J. Pharmacol. \& Exper. Therap., 1953, 109, 107.

14. Remington, J. W., Hamilton, W. F., Wheeler, N. C., and Hamilton, W. F., Jr., Validity of pulse contour method for calculating cardiac output of the $\mathrm{dog}$, with notes on effect of various anesthetics. Am. J. Physiol., 1949, 159, 379.

15. Rashkind, W. J., Lewis, D. H., Henderson, J. B., Heiman, D. F., and Dietrick, R. B., Venous return as affected by cardiac output and total peripheral resistance. Am. J. Physiol., 1953, 175, 415. 
16. Marsh, D. F., Pelletier, M. H., and Ross, C. A., The comparative pharmacology of the N-Alkylaternols. J. Pharmacol. \& Exper. Therap., 1948, 92, 108.

17. Remington; J. W., Hamilton, W. F., Caddell, H. M., Boyd, G. H., Jr., Wheeler, N. C., and Pickering, R. W., Vasoconstriction as a precipitating factor in traumatic shock in the dog. Am. J. Physiol., 1950, $161,125$.

18. Hamilton, W. F., and Remington, J. W., The meas- urement of the stroke volume from the pressure pulse. Am. J. Physiol., 1947, 148, 14.

19. Hamilton, W. F., Riley, R. L., Attyah, A. M., Cournand, A., Fowell, D. M., Himmelstein, A., Noble, R. P., Remington, J. W., Richards, D. W., Jr., Wheeler, N. C., and Witham, A. C., Comparison of Fick and dye injection methods of measuring the cardiac output in man. Am. J. Physiol., 1948, 153, 309. 